\title{
Evaluation of a movement detector to measure daily activity in patients with chronic lung disease
}

\author{
B. Schönhofer*, P. Ardes*, M. Geibel*, D. Köhler*, P.W. Jones*
}

Evaluation of a movement detector to measure daily activity in patients with chronic lung disease. B. Schönhofer, P. Ardes, M. Geibel, D. Köhler, P.W. Jones. CERS Journals Ltd 1997. Eur Respir J 1997; 10: 000-000.

ABSTRACT: This study was designed to evaluate the performance of movement detectors (pedometers) in measuring daily activity of patients with chronic lung disease.

Three groups of subjects were studied: group 1: 25 patients with stable nonhypercapnic chronic obstructive pulmonary disease (COPD) (forced expiratory volume in one second $(\mathrm{FEV} 1)=47 \pm 9 \%$ predicted $)$ studied twice, one month apart; group 2: 25 patients with chronic respiratory failure studied before and three months after nasal nocturnal mechanical ventilation; and group 3: 25 normal healthy subjects studied once.

The median level of activity in the healthy subjects (group 3) was three times greater than in either group of patients (groups 1 and 2). Activity levels were not correlated with age, sex or employment status. The repeatability of the activity counts in the nonhypercapnic COPD patients was high (intraclass correlation coefficient $=0.94$ ) and in these patients activity correlated significantly with FEV1 $(r=0.54, p=0.006)$. In the respiratory failure patients, daytime arterial carbon dioxide pressure $\left(\mathrm{Pa}_{\mathrm{a}}, \mathrm{CO}_{2}\right)$ improved following nasal nocturnal mechanical ventilation (NMV) (pre NMV: $8.5 \pm 1.2$ kPa; post NMV: $6.2 \pm 0.5 \mathrm{kPa})$, health status improved $(\mathrm{p}<0.004)$ and daily movement count doubled $(p<0.0001)$. This increase correlated with change in $\mathrm{Pa}_{\mathrm{a}} \mathrm{CO}_{2}(\mathrm{r}-0.53$, $\mathrm{p}=\mathbf{0 . 0 0 6}$ ), but not with improved health status.

We conclude that motion detectors may provide repeatable measures of daily activity that are related to physiological impairment and improvement following treatment. Activity counts appear to be complementary to estimates of exercise limitation obtained using health questionnaires.

Eur Respir J 1997; 10: 2814-2819.
Krankenhaus Kloster Grafschaft, Zentrum für Pneumologie, Beatmungs- und Schlafmedizin, 57392 Schmallenberg, Germany. **Division of Physiological Medicine, St George' s Hospital Medical School, London, SW

Correspondence: B. Schönhofer Krankenhaus Kloster Grafschaft

Zentrum für Pneumologie, Beatmungs- und Schlafmedizin

57392 Schmallenberg

Germany

Keywords: Chronic obstructive pulmonary disease

chronic respiratory failure

health status

nocturnal mechanical ventilation

pedometers

physical activity

Received: January 271997

Accepted after revision September 91997
Chronic respiratory disease is known to cause a reduction in exercise capacity, whether measured in a formal exercise test or through self-report using scales for dyspnoea or health status ("quality of life"). Exercise tests based upon walking speed are widely used and consistently correlate well with self-reported exercise limitation [1-3]. Such tests are usually performed over a relatively short period, typically a few minutes, and assess exercise tolerance in terms of maximum achievable work rate (in an incremental test) or average work over a period of a few minutes (during timed walking tests). Self-reported exercise impairment measured by dyspnoea scales [2] or health status questionnaires $[4,5]$ assess physical limitation by identifying those activities that are either not possible or are difficult to perform because of breathlessness or fatigue. Neither of these approaches measure the level of activity that the patients, within their physical limitations, at their own pace, are capable of.

This study has been carried out to test the feasibility of using motion detectors (pedometers) to assess the level of activity in patients with chronic lung disease. Three groups of subjects were studied to examine different aspects of the performance of these devices. To assess repeatability, daily activity was measured in an group of nonhypercapnic patients with moderate to severe chronic obstructive pulmonary disease (COPD) on two occasions, one month apart. To examine the response to treatment, patients with chronic ventilatory failure were assessed before and 3 months after being established on home nasal nocturnal mechanical ventilation (NMV). In the third study, an age and sex matched population of healthy disease-free subjects was studied to provide a reference point for normal levels of daily activity as measured using these devices.

\section{Patients and methods}

\section{Movement counting device (pedometer)}

Before carrying out the main study we examined pedometers from four different manufacturers. Four examples of each device were obtained and one of each type was selected as a reference against which the other three were compared. To test reliability, two devices (from the same manufacturer) were worn simultaneously by a healthy subject until the reference device accumulated 5,000 movements. Reliability was considered acceptable if the two devices differed by less than $10 \%$. Only one manufacturer produced motion detectors that met this level of reliability. This device was the Fitty 3 (Kasper \& Richter 
Company, Uttenreuth, Germany). This is a miniature solid-state device costing approximately US $\$ 50$. It is easy to use and is fixed to the trouser or coat belt. One movement in the vertical dimension is registered as a single count. Twenty pedometers of the same type were obtained and tested in the same way. Four did not match the performance of the reference instrument and were discarded. The mean $( \pm \mathrm{SD})$ percentage difference between the four defective devices and the reference device was $18 \pm 35 \%$. In the remaining 16 devices, the mean $( \pm \mathrm{SD})$ percentage difference was $7 \pm 2 \%$.

The sensitivity of the devices to other sources of movement was examined. It was found that vibration associated with car driving would also be registered. To avoid this problem, subjects were asked to record the number of movements accumulated that day before traveling in a vehicle of any form and the number accumulated on leaving the vehicle. The difference was subtracted from the daily total. All assessments of activity were made over a 7 day period. Daily movement counts were recorded on a diary card at the end of each day. In studies that involved repeated measurements of movement in the same subject, the same pedometer was used for each assessment. Studies were performed in three groups of subjects: group 1: patients with COPD but without hypercapnia; group 2: patients with chronic respiratory failure; and group 3: normal healthy controls. The normal subjects and the nonhypercapnic COPD patients were age and sex matched to the respiratory failure patients.

\section{Nonhypercapnic COPD patients}

Twenty five out-patients with moderate to severe chronic airways obstruction were recruited. All were clinically stable and nonhypercapnic. The pedometers were sent to the patients who were then contacted by phone by one of the investigators to ensure that the correct procedure was followed. They completed diary cards recording the total number of movements per day for seven consecutive days prior to spirometric and blood gas measurements in the clinic. This process was repeated 1 month later for another 7 days of recording. Therapy was not changed during this interval.

\section{Respiratory failure patients}

These patients were studied before and after the introduction of NMV. All 41 patients with chronic respiratory failure referred for NMV to the investigating hospital (the Krankenhaus Kloster Grafschaft, Germany), between January and July 1995, were assessed for recruitment to the study. Inclusion criteria were: chronic hypercapnic ventilatory failure (arterial carbon dioxide tension $\left(\mathrm{Pa}, \mathrm{CO}_{2}\right)$ $>6.65 \mathrm{kPa}$ ); stable clinical state with no hospital admission for at least 1 month prior to entry to the study, and no recent deterioration. Exclusion criteria were: rapidly progressive neuromuscular diseases (e.g. progressive amyotrophic lateral sclerosis); acute respiratory failure during the four weeks prior to the study; obstructive sleep apnoea; acute bronchopulmonary infection; fever; haemodynamic instability; severe acidosis; lack of co-operation; and inability to walk unaided (e.g. use of a walking stick).
Thirty patients met the study criteria. All had been referred by chest-physicians and had been treated for at least 6 months with standard conservative therapy appropriate to their condition.

Lung function tests were performed prior to NMV. Normal values for lung function data [6] were used for reference. Tidal volume $(V \mathrm{~T})$ and respiratory frequency $(f \mathrm{R})$ were measured with a portable pneumotachograph. Resting daytime capillary blood gases were measured from the hyperaemic earlobe whilst breathing room air. Peak inspiratory mouth pressure $(P I, \max )$ and peak expiratory mouth pressure $(P E$ E,max $)$ were measured using a piezoelectric pressure sensor (M. Klauke, Krankenhaus Kloster Grafschaft, Germany) using the method of BLACKand HYATI [7]. To reduce any learning effect, the patients practised the pressure measurements for 2 days before the baseline measurements were obtained. On the test days $P \mathrm{I}$,max and $P$ E,max were measured at least five times until a reproducible value was obtained and maximum values were reported.

Breathlessness was measured using the Borg CR-10 scale at the end of a 4 min steady state exercise test at $40 \%$ of the patients' predicted maximum work rate. Healthrelated quality of life was assessed using the St George's Respiratory Questionnaire (SGRQ) [5]. This is a selfadministered disease-specific measure that has been validated in patients with COPD. The questionnaire consists of 50 items with 76 weighted responses divided into three sections: Symptoms, Activity and Impacts. A Total score is derived from all three components. A German translation was used. This had been produced by the process of translation and back-translation using the International Quality of Life Assessment (IQOLA) approach [8]. The scoring for the questionnaire ranges from zero (complete health) to 100 (worst possible). A change in score of 4 units was considered to be clinically significant [9].

The protocol was passed by the Institutional Ethics Committee and written informed consent was obtained. Pre-existing treatment, including drug therapy and longterm oxygen, were continued unchanged throughout the study. The patients did not receive pulmonary rehabilitation or exercise training during the study. For the 7 days before admission to the investigating hospital, the pedometer was applied to the patients under the supervision of their own physician, carer or member of the support services. The patients were also contacted by telephone by one of the investigators to ensure that the correct procedure was being followed. The patients completed diary cards recording the total number of movements per day for seven consecutive days.

All patients were admitted to the investigating hospital for a period of 10-15 days to commence NMV. During this time they were instructed in the use of the ventilator and the interface fit. Ventilator settings were adjusted whilst the patients were awake to obtain optimal ventilation. All patients were initially ventilated via a conventional nose mask. If pressure sores developed or if the quality of ventilation worsened due to leakage from the mask, an individual nose or combined nose-mouth mask was made by a dental laboratory. Two ventilators were used (EV 800, Dräger, Lübeck, Germany and PLV 100; Lifecare, Denver, CO, USA) in the volume cycled mode. Eighteen patients were established with conventional 
nose masks (Respironics mask, Murrysville, USA, n=11; Res-care mask, Sydney, Australia, $n=7$ ). Individual nose masks were used in seven patients and combined nosemouth masks were manufactured for five patients.

The patients were re-admitted to the investigating hospital for reassessment 3 months later. For the 7 days before this, the patients again recorded their movement count using the device they had used previously. They also recorded their daily use of NMV. Whilst in hospital all other assessments were repeated.

\section{Normal subjects}

Twenty five healthy disease-free subjects were recruited. They recorded their activity on each of the seven consecutive days. The healthy subjects were included to provide a reference value of the number of steps that an age- and sex- matched healthy population performed.

\section{Statistical analysis}

Where possible, data were summarized as the mean $( \pm \mathrm{SD})$ and parametric statistics were used. In the respiratory failure patients, the daily movement count was skewed, so data were summarized as the median and interquartile range (IQR) and nonparametric tests were used. Paired comparisons of normally distributed data were tested using paired t-tests, and nonnormally distributed data were tested using the Mann-Whitney U-test. For each subject, the degree of variation in the activity count over the 7 days of recording was expressed as the coefficient of variation, calculated as the standard deviation $(S D)$ of the counts for the 7 days expressed as a proportion of the mean count. Since multiple comparisons were made, statistical significance was accepted at $\mathrm{p}<0.01$.

\section{Results}

\section{Healthy control subjects}

The mean age of the 25 healthy subjects (14 males and 11 females) was $53 \pm 14$ yrs. Eighteen of them were in paid employment. Their mean number of movements per day $( \pm \mathrm{SD})$ was $8,590( \pm 4,060)$. The number of daily movements was not related to age $(r=0.25 ; p>0.2)$, sex $(p=0.5)$, or whether in employment or retired $(\mathrm{p}=0.7)$.

\section{COPD patients}

The mean age of the 25 patients (14 males and 11 females) with COPD was $56 \pm 12$ yrs. Five were in paid employment. The mean forced expiratory volume in one second (FEV1) was $47 \pm 9 \%$ predicted. Their arterial blood gas values were: arterial oxygen tension $\left(\mathrm{Pa}_{\mathrm{a}} \mathrm{O}_{2}\right) 8.4 \pm 1.0$ $\mathrm{kPa}$; and $\mathrm{Pa}, \mathrm{CO}_{2} 5.8 \pm 0.4 \mathrm{kPa}$. Their mean daily movement count was $3,781 \pm 2,320$. Four weeks later their mean daily movement count was $3,626 \pm 2,150$ per day (fig. 1). This difference was nonsignificant (paired t-test; $p>0.1$ ). The intraclass correlation coefficient for the level of daily
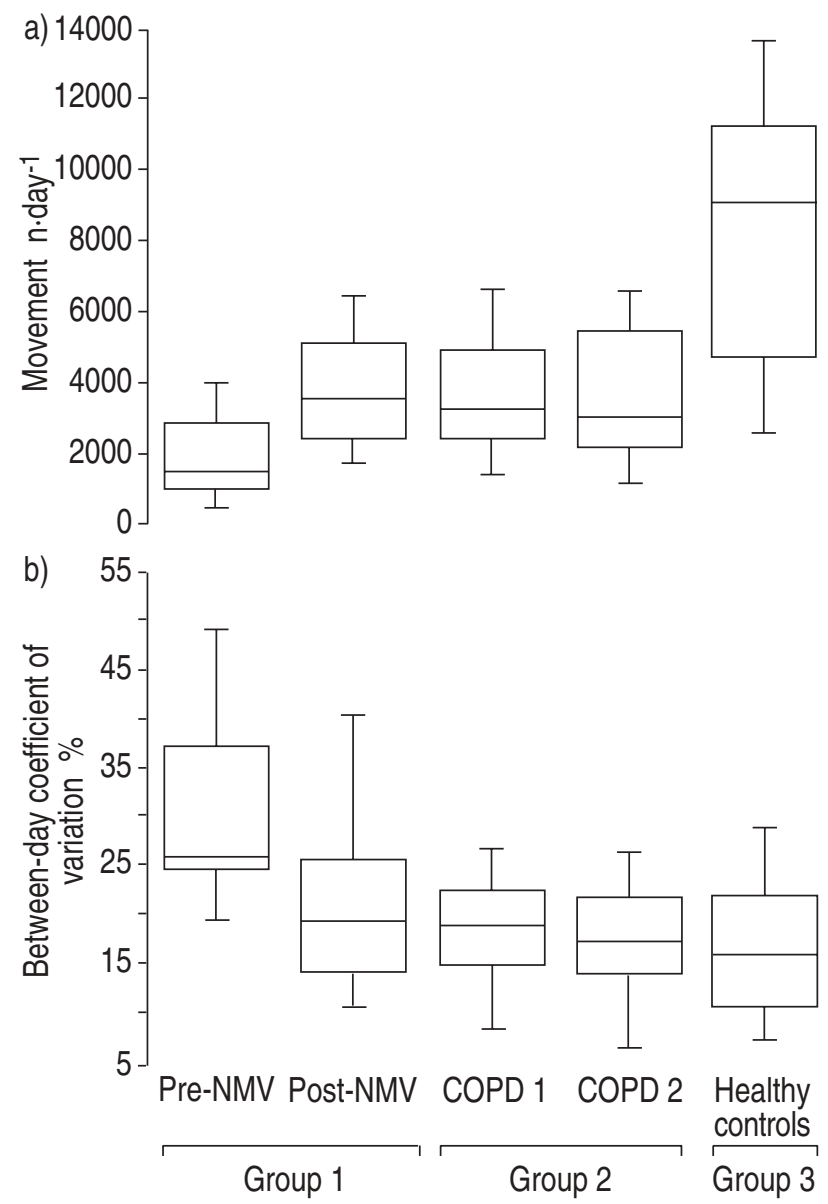

Fig. 1. - a) Box plots for the average daily movement count over 1 week. The results from the three groups of subjects are shown. Group 1: patients with chronic respiratory failure before and three months after starting nocturnal mechanical ventilation (NMV). The increase in steps was significant at $\mathrm{p}<0.0001$ (Mann-Whitney U-test). Group 2: patients with chronic obstructive pulmonary disease (COPD) studied on two occasions 4 weeks apart (COPD 1 and COPD 2, respectively). There was no difference in mean daily movement count $(\mathrm{p}=0.1)$. Group 3 : healthy controls, the mean daily movement count was significantly greater than any of the measurements obtained in the COPD and NMV patients $(\mathrm{p}<0.0001)$. Values are presented as 10th, 25th, 50th (median), 75 th and 90th percentile. b) Box plots for the coefficient of variation in the daily movement count over a 1 week measurement. The coefficient of variation was calculated for each subject with SD expressed as a percentage of the mean.

movement during the two periods was 0.94 . The degree of variation in daily activity, expressed as the between-day coefficient of variation, also did not differ between assessments (fig. 1). The number of movements per day was positively correlated with the FEV1 (fig. 2), but was unrelated to age $(\mathrm{r}=0.19, \mathrm{p}=0.4)$, sex $(\mathrm{p}=0.9)$ and employment $(\mathrm{p}=0.6)$.

\section{Ventilated patients}

Of the 30 patients recruited to the study, five patients at the first assessment failed to use the pedometer correctly or provided incomplete pedometer diary cards. These failures were due to: three patients who forgot to use the device on a daily basis; and two patients who reset the counter on the device. The diagnoses of the remaining patients were: kyphoscoliosis: seven; COPD: six; 


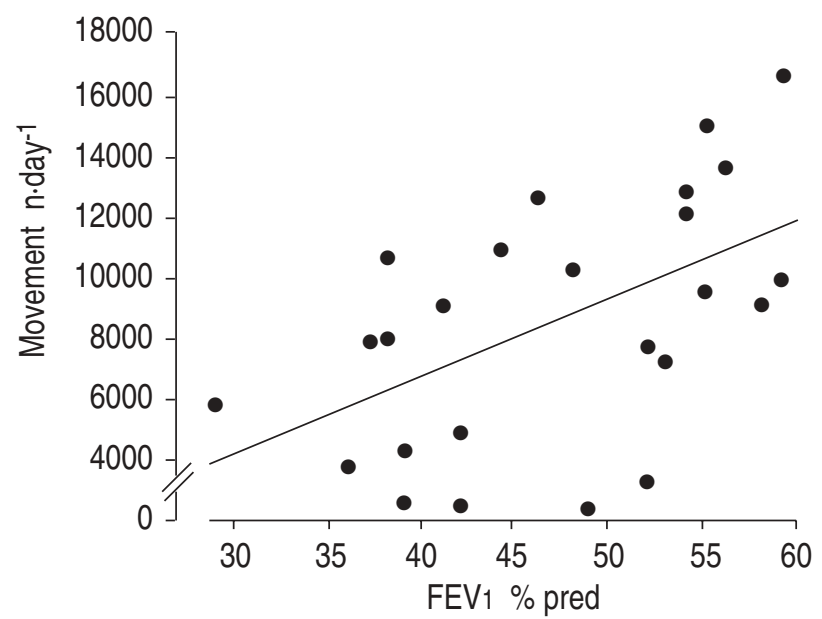

Fig. 2. - Correlation between average daily movement count and forced expiratory volume in one second $\left(\mathrm{FEV}_{1}\right)$ in patients with chronic obstructive pulmonary disease (COPD). The Pearson coefficient (r) value was $0.54(\mathrm{p}=0.006)$. The nonparametric correlation was similar ( $\mathrm{tau}=0.38, \mathrm{p}=0.008)$

Table 1. - Physiological variables of 25 patients with chronic respiratory failure measured before admission, on admission (pre-nocturnal mechanical ventilation (NMV) and after 3 months of home NMV

\begin{tabular}{|c|c|c|c|c|}
\hline & $\begin{array}{c}\text { Pre- } \\
\text { admission }\end{array}$ & Admission & 3 months & p-value \\
\hline$\overline{P a, O_{2}} \mathrm{kPa}$ & $6.5 \pm 1.0$ & $6.3 \pm 1.3$ & $8.3 \pm 1.5$ & $<0.0001$ \\
\hline$P \mathrm{a}, \mathrm{CO}_{2} \mathrm{kPa}$ & $8.5 \pm 1.0$ & $8.5 \pm 1.2$ & $6.2 \pm 0.5$ & $<0.0001$ \\
\hline $\mathrm{pH}$ & $7.35 \pm 0.05$ & $7.34 \pm 0.04$ & $7.40 \pm 0.04$ & $<0.0001$ \\
\hline FEV1 L & - & $0.9 \pm 0.4$ & $1.04 \pm 0.5$ & 0.017 \\
\hline FVC L & - & $1.4 \pm 0.7$ & $1.6 \pm 0.7$ & 0.003 \\
\hline $\begin{array}{l}P_{\mathrm{I}, \max } \\
\mathrm{cmH}_{2} \mathrm{O}\end{array}$ & - & $43 \pm 20$ & $65 \pm 22$ & $<0.0001$ \\
\hline $\begin{array}{l}P \text { E, max } \\
\mathrm{cmH}_{2} \mathrm{O}\end{array}$ & - & $72 \pm 29$ & $101 \pm 35$ & 0.0006 \\
\hline $\begin{array}{l}f \mathrm{R} \\
\text { breaths } \cdot \mathrm{min}^{-1}\end{array}$ & - & $25.2 \pm 4.7$ & $19.6 \pm 4.2$ & $<0.0001$ \\
\hline$V \mathrm{~T} \mathrm{~mL}$ & - & $358 \pm 154$ & $453 \pm 165$ & 0.0002 \\
\hline$t \mathrm{t} / t_{\text {tot }}$ & - & $0.41 \pm 0.05$ & $0.41 \pm 0.4$ & 0.8 \\
\hline $\begin{array}{l}\text { End-exercise } \\
\text { Borg score }\end{array}$ & - & $7.4 \pm 2.3$ & $5.9 \pm 2.0$ & $<0.0001$ \\
\hline
\end{tabular}

Values are presented as mean $\pm \mathrm{SD} . \mathrm{Pa}_{\mathrm{a}, \mathrm{O}_{2}}$ : arterial oxygen tension; $\mathrm{Pa}_{\mathrm{a}} \mathrm{CO}_{2}$ : arterial carbon dioxide tension; $\mathrm{FEV} 1$ : forced expiratory volume in one second; FVC: forced vital capacity; $P \mathrm{I}$,max: peak inspiratory mouth pressure; $P$ E,max: peak expiratory mouth pressure; $f \mathrm{R}$ : respiratory frequency; $V \mathrm{~T}$ : tidal volume; $t \mathrm{I} /$ $t$ tot: ratio of inspiratory time to the duration of the total breathing cycle. Blood gases are daytime measurements. Pre-admission blood gases were measured at the referring hospital. The p-values apply to paired t-tests between measurements made on admission and after 3 months of NMV.

post-polio scoliosis: five; post-tuberculosis (TB): three; thoracoplasty: two; and muscular dystrophies: two. Supplemental oxygen was used in six of the patients with kyphoscoliosis, in one of the post-polio scoliosis patients, in three of the post-TB group and in all the patients with COPD. Three of these patients were in paid employment.

Pre-admission values for blood gases at rest whilst breathing room air were taken by the referring chest physician 4-6 weeks before the study (table 1). This table also contains blood gases taken on admission to the investigat- ing hospital prior to NMV. There was no significant difference between the pre-admission gases and those obtained on admission to hospital, indicating that the patients were in a stable state. The patients' recorded use of NMV at home was $6.9 \pm 1.8 \mathrm{~h} \cdot \mathrm{day}^{-1}$. Their weight did not change over the 3 month period: baseline $62 \pm 18 \mathrm{~kg}$, after NMV $62 \pm 17 \mathrm{~kg} ; \mathrm{p}>0.05$. After 3 months of NMV, daytime $P a, \mathrm{O}_{2}, \mathrm{~Pa}_{2} \mathrm{CO}_{2}$ and $\mathrm{pH}$ all improved significantly (table 1). $V \mathrm{~T}$ rose and the $f \mathrm{R}$ fell. The ratio of inspiratory time to the duration of the total breathing cycle $\left(t \mathrm{t} / t_{\mathrm{t} t \mathrm{t}}\right)$ was unchanged. There were improvements in $P \mathrm{I}, \max$ and $P \mathrm{E}$,max, together with small improvements in forced vital capacity (FVC) and FEV1. Breathlessness for the same level of exercise was reduced (table 1).

The number of movements per day increased significantly (fig. 1). Pre NMV, the median number of movements per day was 1,413 (IQR=1,870); post-NMV median daily movements were 3,553 (IQR=2,676). The between-day coefficient of variation for the movement count fell from $30( \pm 22)$ to $12( \pm 11) \%,(p=0.003)$, as shown in figure 1 . There were significant improvements in the SGRQ scores (indicated by a fall in score) post-NMV: Activity score: pre $78( \pm 13)$, post $65( \pm 22)(\mathrm{p}=0.004)$; Impacts: pre $52( \pm 19)$, post $40( \pm 23)(\mathrm{p}=0.013)$; Total: pre $60( \pm 13)$, post $49( \pm 19)(\mathrm{p}=0.004)$. The Symptoms scores did not change: pre $52( \pm 24)$, post $45( \pm 22)(\mathrm{p}=0.14)$. The improvement in the SGRQ Total score was well above the previously established estimate of a four unit change being clinically significant [9]. At baseline, the number of movements per day correlated weakly with $P \mathrm{I}$,max (Kendal's tau=0.33, p=0.02) and $P \mathrm{a}, \mathrm{CO}_{2}(\mathrm{tau}=0.29, \mathrm{p}=0.04)$. No other correlations with baseline movement count were found and the count was unrelated to age or sex. The increase in daily movement following NMV correlated with the reduction in $\mathrm{Pa}_{\mathrm{a}} \mathrm{CO}_{2}$ (fig. 3), but it was not correlated with changes in any of the other physiological measures or quality of life scores. The improvement in movement count was unrelated to the baseline level of activity (tau $=-0.21, \mathrm{p}=0.15)$, but was correlated with the baseline $P \mathrm{a}, \mathrm{CO}_{2}$ (tau=0.38, $\mathrm{p}=0.007$ ). The fall in between-day variation in movement count following NMV was correlated with the increase in daily movements $(r=0.64 ; \mathrm{p}=0.0006)$, but not with changes in any other physiological variables.

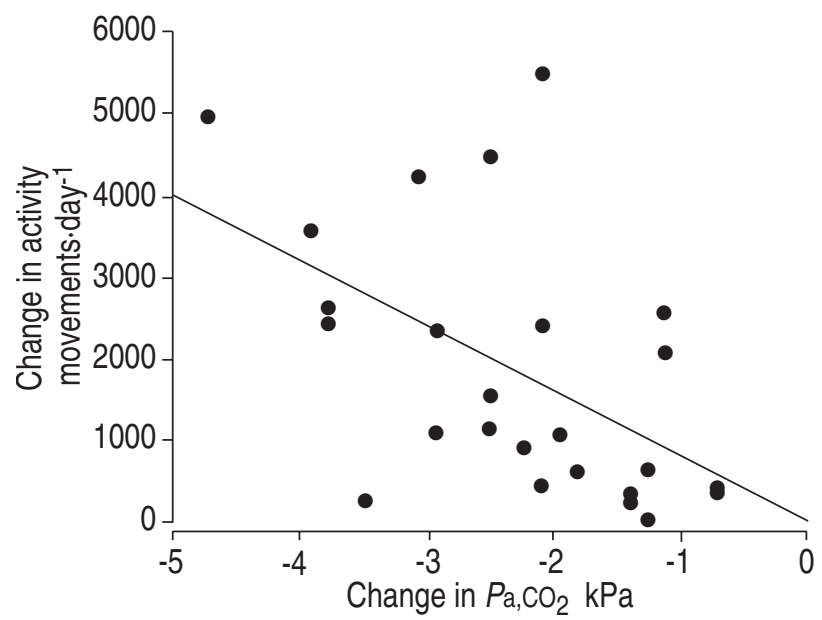

Fig. 3. - Correlation between increase fall in daytime arterial carbon dioxide $\left(\mathrm{Pa}_{\mathrm{a}, \mathrm{CO}_{2}}\right)$ and increase in daily movement count. The Pearson coefficient $(\mathrm{r})$ value was $0.53(\mathrm{p}=0.006)$. The nonparametric correlation was similar $(\operatorname{tau}=0.41, \mathrm{p}=0.004)$. 


\section{Discussion}

This study has shown that it is possible to obtain repeatable measurements of daily activity in patients with severe lung disease using simple pedometers. The level of activity was least in patients with hypercapnic ventilatory failure but increased following NMV to the level observed in nonhypercapnic COPD patients. Both groups of patients had levels of daily movement that were much lower than the average level recorded in age and sex matched healthy subjects. Also, the range of daily activity was very much greater in the normal subjects than in either group of patients. Movement counts from some of the normal subjects suggested that they had a sedentary life-style that contained little more physical activity than some of the patients. The level of daily activity in each group of subjects was unrelated to age, sex or whether they were retired or employed.

Whilst the difference in the level of activity between patients and healthy subjects was large, the degree of variation in daily activity was similar in all three groups of subjects (once the respiratory failure patients had been treated), even though the recording period included both week days and weekends. The variability in the patients with hypercapnia was reduced post-NMV. This may be an important observation since one benefit of treatment may be to reduce the number of "bad days" experienced by patients. It appears that these measurements may provide information about both the quantity and the consistency of daily activity. The number of daily movements correlated quite well with the level of FEV1 in the patients with COPD. The level of correlation was generally better than that reported between walking distance and FEV1 [2, 1012] and comparable to correlations between peak cycleergometer performance and spirometry [13, 14]. In the patients with ventilatory failure, daily activity was correlated weakly with impaired $P \mathrm{I}$,max and $P \mathrm{a}, \mathrm{CO}_{2}$. It appears that daily activity, recorded in this way, is related to some aspects of physiological dysfunction.

Of interest is the absence of any correlation between the activity counts and the patients' breathlessness measured during ergometer exercise, or their scores for the Activity component of the SGRQ. The latter observation is particularly noteworthy since this component of the questionnaire is known to correlate well with 6 min walking distances and the Medical Research Council Dyspnoea Grade [5]. We interpret these findings as evidence that the motion detectors may be assessing a different aspect of exercise tolerance to that measured in the laboratory or by questionnaires. The latter techniques measure exercise limitation either in terms of symptom-limited work capacity or by recording the types of physical activity that are not possible because of dyspnoea. In contrast, motion detectors record levels of activity that patients can manage whilst carrying out their chosen activities at a pace and level of breathlessness that they set themselves. It appears that information provided by motion detectors may be complementary to that obtained using more established methods.

This study was not designed to test the efficacy of NMV; however, in the patients with chronic respiratory failure, there were improvements in a range of physiological measures following NMV. Health status also improved significantly, confirming recent findings in patients with
COPD receiving nocturnal pressure support [15]. The effect of NMV on endurance tests has not been studied systematically although walking distance tests have been performed. The improvements seen have been small or nonsignificant [15-17]. It was not possible to perform such tests in this study, but it would be of considerable interest to compare laboratory estimates of exercise tolerance or capacity with those obtained during unrestricted voluntary daily activity. In the current study, the improvement in blood gases was accompanied by a twofold increase in the number of movements recorded per day. We suggest that the improvement in daily movement was not a chance finding, but was attributable to the introduction of NMV for two reasons. Firstly, we have shown that the repeatability of the daily movement counts in other patients with severe airways obstruction was high and showed no trend for spontaneous improvement over time. Secondly, the increase in activity in the respiratory failure patients was greatest in those with the most severe hypercapnia and correlated with the fall in $\mathrm{Pa}_{\mathrm{a}} \mathrm{CO}_{2}$. This improvement was unrelated to the baseline level of activity suggesting that the improvement was real and not due to "regression to the mean".

The devices used in this study are often termed "pedometers", implying that they measure the number of steps taken. In this report, however, we have been careful to describe the counts obtained as measures of activity since the device detects vertical motion not movement of the legs. It was not the purpose of this study to calculate the level of patients' activity in absolute units such as distance worked, speed of walking or energy consumed. Our objective was to test the feasibility of using these devices in a clinical research setting. It is reasonable to assume that most of the vertical movements counted by the device were related to walking since it was worn at the waist whilst the subject was dressed, and the effects of extraneous factors such as vibration from riding in vehicles were excluded. It is not possible from this study to convert the number of movements recorded into distance walked since this would have depended on an individual's stride length. To quantify the distance covered or work performed, calibration would be required for each individual, but even then it cannot be assumed that stride lengths and movement patterns obtained in the exercise laboratory will correspond to those used in normal daily life. These considerations reflect the difficulty in identifying a "gold standard" measure of actual (as opposed to reported) daily activity against which to test the accuracy and reliability of these devices. Indeed, no such measure exists.

More research is required in this area and further studies of the impact of treatment for chronic respiratory disease on daily physical activity are needed. Sophisticated computerized actigraphs and accelerometers are now available for assessing temporal and spatial movement parameters $[18,19]$, but, they are expensive. Large scale studies require simple and cheap devices. This study has shown that such instruments may be sufficiently reliable and sensitive to register changes in physical activity following therapy.

\section{References}

1. O'Reilly JF, Shaylor JM, Fromings KM, Harrison BDW. The use of the 12 minute walking test in assessing the 
effect of oral steroid therapy in patients with chronic airways obstruction. Br J Dis Chest 1982; 76: 374-382.

2. Mahler DA, Weinberg DH, Wells CK, Feinstein AR. Measurements of dyspnoea. Contents, interobserver correlates of two new clinical indices. Chest 1984; 85: 751758.

3. Guyatt GH, Thompson PJ, Berman LB, et al. How should we measure function in patients with chronic lung disease? J Chron Dis 1985; 38: 517-524.

4. Guyatt GH, Berman LB, Townsend M, Pugsley SO, Chambers LW. A measure of quality of life for clinical trials in chronic lung disease. Thorax 1987; 42: 773-778.

5. Jones PW, Quirk FH, Baveystock CM, Littlejohns P. A self-complete measure for chronic airflow limitation - the St George's Respiratory Questionnaire. Am Rev Respir Dis 1992; 145: 1321-1327.

6. Quanjer PH, Dalhuijsen A, Van Zomeren BC. Summary equations of reference values. Bull Europ Physiopath Resp 1983; 19: 45-51.

7. Black LF, Hyatt RE. Maximal respiratory pressures: normal values and relationship to age and sex. Am Rev Respir Dis 1969; 99: 696-702.

8. The IQOLA Project Team (1994). Translating health: the International Quality of Life Assessment (IQOLA) project. Qual Life Res 1994; 3: 66.

9. Jones PW, Quirk FH, Baveystock CM. The St George's Respiratory Questionnaire. Respir Med 1991; 85: 25-31.

10. McGavin CR, Gupta SP, McHardy GJR. Twelve minute walking test for assessing disability in chronic bronchitis. Br Med J 1976; 1: 822-823.

11. McGavin CR, Artvinli M, Naoe H, McHardy GJR. Dysp- noea, disability and distance walked: comparison of estimates of exercise performance in respiratory disease. $\mathrm{Br}$ Med J 1978; 2: 241-243.

12. Swinburn CR, Wakefield JM, Jones PW. Performance, ventilation and oxygen consumption in three different types of exercise test in patients with chronic obstructive lung disease. Thorax 1985; 40: 581-586.

13. Carter R, Peavler M, Zinkgraf S, Williams MS, Fields S. Predicting maximal exercise ventilation in patients with chronic obstructive pulmonary disease. Chest 1987; 92: 252-259.

14. Matthews JL, Bush BA, Ewald FW. Exercise responses during incremental and high intensity and low intensity steady state exercise in patients with obstructive lung disease and normal control subjects. Chest 1989; 96: 11- 17.

15. Meecham Jones DJ, Paul EA, Jones PW, Wedzicha JA. Nasal pressure support ventilation plus oxygen compared with oxygen therapy alone in hypercapnic COPD. Am $J$ Respir Crit Care Med 1995; 152: 538-544.

16. Goldstein RS, De Rosie JA, Avendano MA, Domagne TE. Influence of noninvasive positive pressure ventilation on inspiratory muscles. Chest 1991; 99: 408-415.

17. Renston JP, DiMarco AF, Supinski GS. Respiratory muscle rest using BiPAP ventilation in patients with stable severe COPD. Chest 1994; 105: 1053-1060.

18. Morris JRW. Accelerometry - a technique for the measurement of human body movement. J Biomechanics 1973; 6: 729-736.

19. Melanson EL, Freedson PS. Validity of computer science and application, Inc (CSA) activity monitor. Med Sci Sports Exerc 1995; 27: 934-940. 